\title{
LUCAS JOSÉ D'ALVARENGA, TRADUTOR DE SAFO
}

\author{
Felipe Coelho de Souza Ladeira ${ }^{1}$ \\ Gracinéa Imaculada Oliveira ${ }^{1}$ \\ 1'Faculdade de Ciências Sociais Aplicadas de Belo Horizonte \\ Belo Horizonte, Minas Gerais, Brasil
}

Resumo: Este artigo analisa a retradução de uma ode de Safo, feita por Lucas José d'Alvarenga, em 1830. Nesta análise, cotejou-se a retradução de Alvarenga com o texto-fonte e com cinco traduções diferentes, a partir dos conceitos de autoria de Venuti e de retradução de Bergman.

Palavras-Chave: Alvarenga; Retradução; Autoria; Safo.

\section{LUCAS JOSÉ D'ALVARENGA, SAPPHO'S TRANSLATOR}

\begin{abstract}
This paper aims at examining the retranslation of a Sappho's ode, made by Lucas José d'Alvarenga in 1830. Taking into account his own work and five other translations, a comparison was made using the concept of authorship from Venuti and the retranslation from Berman Keywords: Alvarenga; Retranslation; Authorship; Sappho.
\end{abstract}

\section{Introdução}

Lucas José d'Alvarenga é daqueles escritores que, tendo produzido em época de transição, apresenta uma obra híbrida, em que se mesclam elementos de estilos em decadência e traços de uma nova sensibilidade artística. Nascido em 1768 em Sabará (MG) e falecido no Rio de Janeiro, em 1831 (OLIVEIRA, 2016), Alvarenga publicou seus livros no início do século XIX, época 
considerada por Candido (2000) como crucial para a consolidação da literatura brasileira.

Formado em Leis pela Universidade de Coimbra, retornou ao Brasil onde exerceu alguns cargos públicos em sua cidade natal. Entre 1809 e 1810, foi governador de Macau, evento que marcou suas futuras publicações. Durante sua administração, conseguiu expulsar os piratas chineses que infestavam a região e fechar um acordo diplomático com os ingleses, obtendo a retirada de suas tropas da ilha (ALVARENGA, 1828; 1830). Essas experiências motivaram seus três livros de memórias.

Além dessas obras memorialísticas, Alvarenga escreveu uma novela - Statira, e Zorastes (1826), primeira do gênero publicada no Brasil e um livro de poesias - Poezias (1830). Neste livro há cerca de 50 poemas como cantigas, epigramas, vilancetes, etc. Destacam-se também, pela quantidade, os sonetos e os improvisos, sendo que estes ilustram a faceta repentista do poeta. Além disso, Alvarenga traduziu uma ode de Safo e comentou outras traduções desse poema, assunto desta pesquisa.

Tendo como texto de partida uma versão latina, publicada em Londres, em 1742, Alvarenga traduziu o fragmento 31 de Safo e apresentou outras traduções, feitas por Boileau, pelo Abade Delille, por Francis Fawkes e pelo Desembargador Magalhães. Ao fazer isso, Alvarenga apresenta uma pequena explanação sobre esses textos e sobre o próprio ato de traduzir. Esse material é muito importante para o campo da Tradução, já que permite vislumbrar seu conceito no início do século XIX e também confrontar diferentes propostas de tradução de um dos versos da mais famosa poetisa da Antiguidade, que muita influência exerce na literatura ocidental até hoje. Levando isso em consideração, propomos: 1- apresentar, brevemente, o caminho pelo qual o fragmento 31 de Safo foi vertido em latim para a edição inglesa de 1742, fonte de Alvarenga; 2- analisar sua tradução, confrontando-a com a versão latina e comparando-a com alguns aspectos das traduções francesas, inglesa e a do Desembargador Magalhães. Esse cotejo foi norteado pelos conceitos de autoria 
e de tradução de Venuti (1996) e, também, pela concepção de retradução, de Berman (1990).

\section{Safo, Catulo e a edição latina de 1742}

É inegável a influência grega na formação da Literatura Latina. Por volta de 250 a.C., Lívio Andronico traduziu a Odisseia para o latim, fundando a poesia épica romana e sendo seguido por vários outros poetas e autores nas décadas seguintes. Essa troca cultural repercutiu fortemente no fazer literário romano e produziu diferentes reflexões a respeito do processo de tradução. Públio Terêncio Afro, quase um século depois de Andronico, foi um dos primeiros a deixar registrado uma crítica. Rebatendo uma acusação de 'mau poeta' feita por um adversário, Terêncio declara, no prólogo de sua comédia Eunuco, que seu caluniador "vertendo bem e escrevendo mal, de boas peças gregas fez comédias ruins ${ }^{1}$ ”. Assim, influenciados pela Literatura Grega, os autores latinos se serviram de modelos pré-existentes como fonte para traduções mais ou menos livres ou como inspiração para suas próprias recriações.

Cem anos após Terêncio, Cícero retoma a questão da tradução numa passagem do De optimo genere oratorum. Ao justificar o procedimento adotado em suas traduções de oradores gregos, Cícero afirma que "não traduzi como intérprete, mas como orador [...] não tive necessidade de traduzir palavra por palavra, mas mantive o gênero das palavras e sua força ${ }^{2}$ ". Contemporâneo de Cícero, Catulo escreveu dois poemas que são traduções, ou recriações dos originais gregos: o poema 51, modelado no fragmento 31 de Safo, e o poema 66, baseado no fragmento 110 de Calímaco.

O fragmento 31 de Safo descreve a reação de um eu lírico diante da pessoa amada, não identificada. A estrutura do poema permite diferentes interpretações. De um lado, pode-se imaginar que o eu

${ }^{1}$ Terêncio, Eunuco, v. 7-8. Tradução de Fujihara (2006, p. 57).

${ }^{2}$ Cícero, De optimo genere oratorum. Tradução de Mauri Furlan (2001, p. 17). 
lírico observa a interação entre a pessoa amada e um personagem masculino, identificado apenas como "aquele" ( $\kappa \tilde{\eta} \nu o s)$ Por outro lado, esse mesmo pronome masculino pode ser entendido como uma generalização, criando um sentido próximo de "Feliz aquele, quem quer que seja, que está próximo de ti”. Essa escolha afeta diretamente a interpretação do sexto verso, pois o 'estremecimento' pode ser provocado pela emoção afetiva (despertada pela proximidade, voz e sorriso) ou pela angústia de um ciúme (ao vê-la tão próxima e entretida por um homem belo, par dos deuses). A estrutura inicial do poema, então, permite uma leitura ambígua ou aberta (WILLS, 1967, p. 170). Dessa forma, a descrição fisiológica, que se inicia no sexto verso e culmina na terceira estrofe, pode ter diferentes interpretações possíveis: dor e aflição para alguns, excitação e orgasmo para outros.

Quadro 1 - Fragmento 31 de Safo e tradução.

\begin{tabular}{|c|c|}
\hline 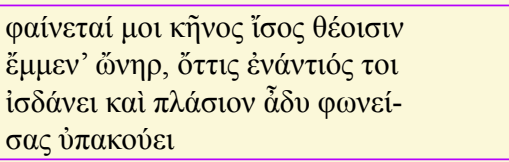 & $\begin{array}{l}\text { Ele }^{3} \text { me parece ser par dos deuses, } \\
\text { O homem que se senta perante ti } \\
\text { E se inclina perto pra ouvir tua doce } \\
\text { Voz e teu riso }\end{array}$ \\
\hline 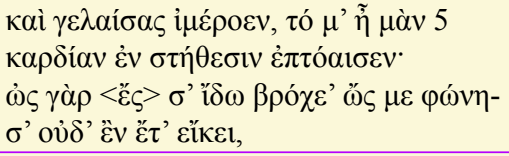 & $\begin{array}{l}\text { Pleno de desejo. Ah, isso, sim, } \\
\text { Faz meu coração 'stremecer no peito. } \\
\text { Pois tão logo vejo teu rosto, a voz } \\
\text { Perco de todo. }\end{array}$ \\
\hline 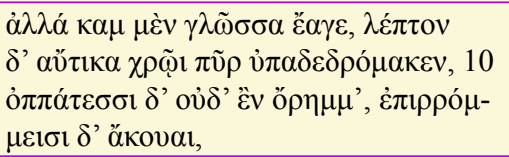 & $\begin{array}{l}\text { Parte-se-me a língua. Um fogo leve } \\
\text { Me percorre inteira por sob a pele. } 10 \\
\text { Com os olhos nada mais vejo. Zumbem } \\
\text { Alto os ouvidos. }\end{array}$ \\
\hline 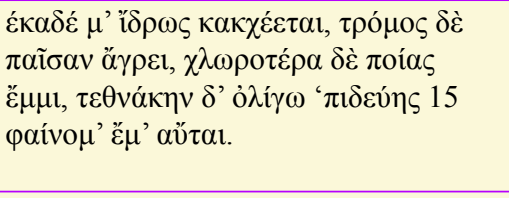 & $\begin{array}{l}\text { Verto-me em suor. Um tremor me toma } \\
\text { Por completo. Mais do que a relva } \\
\text { estou } \\
\text { Verde e para a morte não falta muito } 15 \\
\text { É o que parece. }\end{array}$ \\
\hline 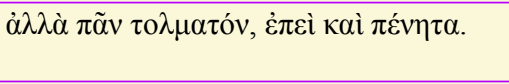 & $\begin{array}{l}\text { Mas tudo se pode suportar, posto que } \\
\text { mesmo a um pobre. }\end{array}$ \\
\hline
\end{tabular}

Fonte: ANTUNES, 2009, p. 141.

${ }^{3}$ Aqui, o tradutor optou por utilizar "ele" no lugar de "aquele". 
À primeira vista, o poema 51 de Catulo aparenta ser uma tradução de Safo. Entretanto, podemos destacar duas mudanças significativas: o vocativo Lesbia (v. 7) e a última estrofe.

\section{Quadro 2 - Poema 51 de Catulo e tradução.}

\begin{tabular}{|l|l|}
\hline $\begin{array}{l}\text { Ille mi par esse deo videtur, } \\
\text { ille, si fas est, superare divos } \\
\text { qui sedens adversus identidem te } \\
\text { spectat et audit }\end{array}$ & $\begin{array}{l}\text { Ele } 4 \text { parece-me ser par de um deus, } \\
\text { ele, se é fás dizer, supera os deuses, } \\
\text { esse que todo atento o tempo todo } \\
\text { contempla e ouve-te }\end{array}$ \\
\hline $\begin{array}{l}\text { dulce ridentem, misero quod omnis } 5 \\
\text { eripit sensus mihi: nam simul te, } \\
\text { Lesbia, adspexi, nihil est super mi } \\
<\text { vocis in ore }>\end{array}$ & $\begin{array}{l}\text { doce rir, o que pobre de mim todo } \\
\text { sentido rouba-me, pois uma vez } \\
\text { que te vi, Lésbia, nada em mim sobrou } \\
\text { (de voz na boca) }\end{array}$ \\
\hline $\begin{array}{l}\text { lingua sed torpet, tenuis sub artus } \\
\text { flamma demanat, sonitu suopte } 10 \\
\text { tintinant aures, gemina teguntur } \\
\text { lumina nocte. }\end{array}$ & $\begin{array}{l}\text { mas torpece-me a língua e leve os } \\
\text { membros } \\
\text { uma chama percorre e de seu som }\end{array}$ \\
\hline $\begin{array}{l}\text { Otium, Catulle, tibi molestum est: } \\
\text { otio exsultas nimiumque gestis: } \\
\text { otium et reges prius et beatas } 15 \\
\text { perdidit urbes. }\end{array}$ & $\begin{array}{l}\text { O ócio, Catulo, te faz tanto mal. } \\
\text { No ócio tu exultas, tu vibras demais. } \\
\text { O ócio já reis e já ricas cidades } \\
\text { antes perdeu. }\end{array}$ \\
\hline
\end{tabular}

Fonte: OLIVA NETO, 1996, p. 102.

Como observado por Polt (2007, p. 114), o primeiro verso de Catulo "Aquele me parece ser par de um deus" (Ille mi par esse deo uidetur) é o mais próximo possível de uma tradução palavra por palavra, pois todas as palavras gregas de Safo estão representadas em Catulo e, salvo duas, seguem a mesma ordem do original $^{5}$. Essa correspondência teria uma importante implicação: gerar uma expectativa na audiência de uma tradução literal. Contudo, o segundo verso de Catulo é diferente do de Safo. Assim, logo nos dois primeiros versos do poema, Catulo constrói e quebra uma expectativa de tradução, estabelecendo uma intertextualidade com

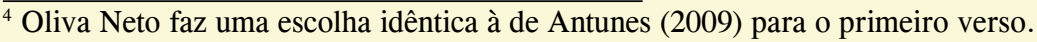

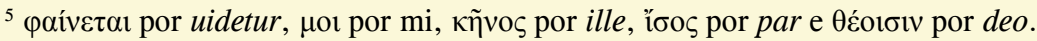


Safo e, ao mesmo tempo, reforçando a originalidade de seu poema, que culminará na última estrofe.

A partir do terceiro verso, Catulo retoma sua tradução de Safo, mas incorpora pequenos elementos que reforçam a sua apropriação, como a utilização de Lesbia para identificar a pessoa amada. Polt (2007, p. 119) ressalta ainda que, ao fazer isso, Catulo fortalece a conexão de sua tradução com o restante de seu corpus e ao mesmo tempo estabelece outra inteligente reafirmação intertextual da procedência de seu texto. Ao empregar o termo Lesbia, Catulo produz uma ambiguidade com o nome, podendo se referir tanto a sua própria amada (ou 'musa inspiradora'), Clódia', quanto à mais famosa poetisa da ilha de Lesbos.

A terceira estrofe de Catulo retoma o poema de Safo e, de acordo com Polt (2007, p. 126), existem estudos que sugerem que Catulo tenha incorporado a terceira e a quarta estrofes de Safo em uma única. Seja qual for o caso, o significado e a função da quarta estrofe de Catulo são temas de amplo debate. Muitas vezes encarado apenas como uma tradução de Safo, o poema de Catulo sofreu, inclusive, "correções" da parte de editores. A edição da Loeb Classical Library, de 1922, por exemplo, apresenta a quarta estrofe de Catulo como um fragmento separado do todo, nomeado poema 51a.

Em 1586, Henri Estienne (Henricus Stephanus) publicou uma tradução comentada, em latim, das Odes de Píndaro e incluiu, também, poemas de outros oito poetas líricos gregos. Na página 28 da seção correspondente a Safo, Henri apresenta o texto em grego do fragmento $31 \mathrm{com}$ o título ПАРА $\triangle \mathrm{IONY} \Sigma \mathrm{I} \Omega$ (junto de Dioníso). Ao lado, na página seguinte, com o mesmo título traduzido para o latim, APUD DIONYSIUM, Estienne informa que o texto de Safo havia sido retirado da obra de Longino, Sobre o Sublime, e apresenta o poema 51 de Catulo considerando-o uma tradução (interpretatio) de Safo. Em seguida, Estienne esclarece que suprimira

\footnotetext{
${ }^{6}$ Seria esse o verdadeiro nome de Lesbia na poesia de Catulo, se levarmos em conta a afirmação de Apuleio em Apologia 10.
} 
a última estrofe de Catulo para oferecer uma tradução própria para a quarta estrofe de Safo:

Quadro 3 - Texto latino presente na edição de 1586 e tradução. APVD DIONYSIVM

Longinum, in libro de sublimi genere dicendi.

Catulli interpretatio, postremis quatuor versibus exceptis, qui sunt $\mathrm{He}$ rici Stephani
[...]
[...]

Cypria aspexi, nihil est super mi 7

$$
[\ldots]
$$

Manat \& sudor gelidus, tremórq; Occupat totam : uelut herba, pallét Ora : spirandi neq; compos, orco 15 Proxima credor.

$[\ldots]$
Cípria, assim que te vi, nada restou
em mim 7
$[\ldots]$
um frio suor corre, e um
estremecimento
me ocupa toda: assim como a
grama, meu
rosto perde a cor: não sou capaz de
respirar, 15
da morte me sinto próxima.

Fonte: ESTIENNE, 1586, p. 29, tradução nossa.

Estienne não menciona, contudo, a substituição do nome Lesbia por Cyprea ${ }^{7}$. Como o manuscrito mais antigo dos poemas de Catulo data do século IX, podemos supor que essa alteração tenha sido intencional. Como em Safo não existe qualquer menção à identidade da pessoa amada, Estienne buscaria, com o epíteto da Deusa do Amor, uma solução mais abrangente para a sua própria tradução de Safo, modulada pelo poema de Catulo.

Para sua tradução do fragmento 31 de Safo, Lucas José d'Alvarenga informa que se baseou na "Tradução Latina de Lon-

${ }^{7}$ Epíteto de Afrodite. Em um dos mitos sobre sua criação, a deusa, logo que emergiu do mar, foi transportada para a ilha de Citera e depois até a costa de Chipre (GRIMAL, 2000, p.10). Dai o termo grego Kvлpı $\alpha$, que resultará em Cypria para o latim. 
dres em 1742". Esta obra ${ }^{8}$ compila os poemas completos de Anacreonte e os fragmentos de Safo, todos traduzidos e comentados em latim. Assim como no livro de 1586, a edição latina de 1742 apresenta o fragmento 31 grego na página esquerda, dessa vez sem título, com sua tradução latina na página seguinte, intitulada In puellam: ex Catulli interpretatione. Antecedendo a quarta estrofe, segue a informação Reliqua sunt Henrici Stephani (deixados por Henri Estienne).

\section{A retradução de Alvarenga a partir da edição latina de 1742}

Alvarenga, além de informar o texto-fonte de sua tradução, analisa as traduções do fragmento da ode de Safo. Um dos problemas que ele aponta para a quantidade de traduções que existem desse texto é o da divergência. Para ele, isso foi ocasionado pela "excessiva liberdade, que tomárão, os Traductores de corrigir, ou alterar á seu grado hum Escrito, do qual não apparecia o Autographo" (ALVARENGA, 1830 , p. 107), reproduzindo a opinião de Vossio. Com isso, ele aponta um fato importante para este campo de estudos: a tradução de apógrafos, questão que aproxima esse campo da Filologia. Embora levante o problema, ele não o aprofunda, já que considera que o conflito nas variações das traduções advém da excessiva liberdade que os tradutores se deram, aproveitando-se da ausência do autógrafo. Entretanto é importante ressaltar que é problemático afirmar que os tradutores se deram tal liberdade deliberadamente, já que traduziram apógrafos diferentes, como ele mesmo comenta.

Apesar de não deixar explícito, Alvarenga não considera bem essas variações, fato que é perceptível pelo título que dá à sua tradução: "Versão litteral do fragmento de huma ode de Sapho" (ALVARENGA, 1830, p.103) e, também, por julgar importante que o leitor tenha pelo menos duas traduções dessa ode que não divirjam:

${ }_{8}^{8}$ Anacreontis Teii Carmina. Londini: Imprensis S. Birt, 1742. 
“Eu liguei-me á Traducção Latina de Londres, principalmente para que entre tantas Traducções, e todas differentes entre si, houvessem ao menos duas, que se ajustassem" (ALVARENGA, 1830, p. 108). Para ele, essas variações indicam desordem e confusão de ideias, o que não condiz com a produção poética de Safo. Em síntese, Alvarenga advoga que as traduções não devem apresentar discordância (ou apresentar o mínimo possível) e devem estar o mais próximo possível do texto original, mesmo se tratando de um texto poético. Isso demonstra que, para ele, a tradução deve ser “expressão da intenção do autor estrangeiro", ideia que, segundo Venuti (1996, p. 99), permeia as culturas francesa e inglesa desde o século XVII, e da qual Alvarenga comunga.

Embora esse poeta afirme que fez sua tradução devido à beleza do texto de Safo, há outro motivo que está implícito nessas reflexões: a sua insatisfação com as traduções já feitas, sobretudo com o excesso de liberdade, assim chamado por ele, dos demais tradutores. Isso não significa que ele tenha desmerecido as demais, mas que quis marcar sua contribuição a partir de uma tradução, baseada em Catulo, que ele julga mais próxima à do texto grego.

Essa postura converge para a de Berman (2017, p. 262), para quem "a necessidade da retradução est[á] inscrit[a] na própria estrutura do ato de traduzir". Considerando que a retradução abrange, além das traduções feitas diretamente da língua de partida do texto original, as feitas a partir de uma língua intermediária, Berman (2017) problematiza essa questão, ao afirmar que toda grande tradução é uma retradução, embora nem toda retradução seja uma grande tradução. Para isso, introduz dois conceitos-chave: o de Kairos e o de Insuficiência. Grosso modo, o kairos seria uma categoria temporal e diria respeito ao momento oportuno em que, após muitas introduções eruditas, adaptações, "torna-se possível inscrever a significância de uma obra em nosso espaço linguístico" (BERMAN, 2017, p. 266-267). Já a insuficiência é condição do próprio ato de traduzir, já que, para ele, "toda tradução é marcada pela "não-tradução'” (BERMAN, 2017, p. 266). 
Essa insuficiência, ou melhor, a não-tradução, é percebida por Lucas José d'Alvarenga nas demais propostas de tradução do fragmento 31 de Safo:

E eis o motivo porque inseri aqui varias Traducções; e porque eu mesmo tambem a traduzi [...] Todas porém differem mais ou menos humas das outras sem que possa affirmar-se ao certo, qual he a que mais se conforma com o Original; e dahi procede ignorar-se: $1 .^{\circ}$, qual foi o motivo, ou emoção amorosa, que deo ocazião á ella. $2 .^{\circ}$, por quem, e á quem se deve suppor dirigida. (ALVARENGA, 1830, p. 104-105)

Quanto ao primeiro ponto acima, Alvarenga supõe que Safo quis exprimir "os furores, e commoções do amor; e por isso colligio pela maneira mais bela, e sublime de todas as circunstancias, e accidentes, que acompanhão esta paixão" (ALVARENGA, 1830, p. 105). Contudo, em seguida, Alvarenga afirma que o "Doutor Pearce" discorda dessa visão, que Safo, na verdade, desejara descrever "os transportes, e angustias do Ciume, e raiva, que a agitavão”. Quanto ao segundo ponto mencionado acima, Lucas observa que não existe um consenso entre as traduções com relação ao eu lírico: ora é visto como o de um amante dirigindo-se a sua amada, ora o de uma "Dama" dirigindo-se a Vênus.

Para Lucas, esses pontos serão determinantes para se compreender as diferentes traduções do poema de Safo. Ao mesmo tempo, são essas insuficiências que permitem "melhor se observarem estas antinomias, e se admirarem ao mesmo tempo as graças, e bellezas de cada huma das Traducções desses grandes homens" (ALVARENGA, 1830, p. 106). 


\subsection{A retradução de Alvarenga a partir da Edição Latina de $\mathbf{1 7 4 2}$ da Ode de Safo: questões de autoria}

Alvarenga discute a questão da "tradução x autoria" em sua explanação sobre as retraduções da ode de Safo. Mesmo considerando que o objetivo da tradução é manter a intenção do autor do texto original, ele reconhece que as singularidades das demais traduções não diminuem a beleza do texto traduzido. Levando isso em conta, foi feito o cotejo entre a sua retradução e a da edição latina de 1742 .

Alvarenga demonstra conhecer o poema original de Catulo, pois informa em nota que este dirige sua ode a Lésbia, não a Cípria. Mesmo assim, usou como texto de partida a tradução de Londres de 1742, mantendo, consequentemente, o vocativo Cípria na sua retradução, como se percebe no quadro abaixo. Isso pode ser justificado pelo seu interesse em apresentar duas traduções "que se ajustassem", frente as outras "[...] diferentes entre si” (ALVARENGA, 1830, p. 108).

Quadro 4 - A retradução de 1742 e a de Alvarenga.

Traducçaõ Latina de Londres em 1742 .

In puellam: ex Catulli interpretatione.

(a)

Ille mi par esse Deo videtur, Ille, si faz est, superare Divos, Qui sedens adversus identidem te Spectat et audit$$
\text { (a) }
$$

VERSÃO LITTERAL DO

FRAGMENTO DE HUMA ODE DE SAPHO

Conforme a Traducção Latina de

Londres em 1742. (*)

ODE.

1.

Eu creio igual aos Deozes,

Que excede, (se he possivel)

Quem quer que unido á ti

Te vê, te escuta. 
Dulce ridentem; miserae quod omnes Eripit sensus mihi. Nam simul te, Cyprea, aspexi nihil est supèr mi, Quod Loquar âmens.

Lingua sed torpet, tenues sub artus

Flamma demanat, sonitu suepte

Tentinant aures ; gemina et teguntur Lumina nocte.

Reliqua sunt Henrici Stephani.

Manat et sudor gelidus, tremorque Occupat totam: velut herba pallent Ora: spirandi neque compos, Orco Proxima credor. $2^{a}$

Teus meigos risos, Cypria,

Me encantão: quando os vejo

Perco a voz, os sentidos;

Fico n'hum delirio.

$3^{\mathrm{a}}$

Assim de vêa em vêa

Corre flamma electrica;

Susurrão-me os ouvidos,

Turvão-se-me os olhos.

$4^{\mathrm{a}}$

Em gelidos suores,

Sem alento, languida, Fria, pallida, tremula

Eu morrer me sinto.

(a) Catullo dirige a Ode a Lesbia, e não a Cypria.

Fonte: ALVARENGA, 1830, p. 103-109.

Alvarenga chama seu texto de uma "versão litteral", apresentando, inclusive, muitas inversões sintáticas na primeira estrofe, para tentar se manter fiel ao texto latino. A primeira cena do poema, por exemplo, mostra que, para o eu lírico, qualquer pessoa que ouça e veja a amada, estando junto dela, é igual e, quiçá, superior aos deuses, o que reproduz o texto-fonte. Entretanto há marcas de autoria em sua retradução.

$\mathrm{Na}$ primeira estrofe, percebe-se um deslocamento de foco, o que diferencia a retradução de Alvarenga das demais que ele apresenta em seu livro. Essa mudança de perspectiva incide nos sujeitos da cena, visto que nas traduções de Boileau, de Delille, de Francis Fawkes e de Magalhães, a focalização ${ }^{9}$ ocorre no sujeito que está

${ }^{9}$ Focalização [é] o ato de [...] pôr em relevo/realce/ evidência um determinado item do texto, seja (a) com o uso de estratégias propriamente textuais, como 
(ou possa estar) junto à amada: "Heureux, qui pres de toi pour toi seule soupire [...]" (BOILEAU apud ALVARENGA, 1830, p. 110); "Heureux celui qui pres de toi soupire [...]" (DELILLE apud ALVARENGA, 1830, p. 111); "More happy than the Gods is he [...]" (FAWKES apud ALVARENGA, 1830, p. 112); "Se alguem no mundo existe igual aos Deozes [...]" (MAGALHÃES apud ALVARENGA, 1830, p. 113).

Na tradução de Catulo, já transcrita anteriormente, o foco também é nesse sujeito - "Ille"10, que inicia os dois primeiros versos. Já na tradução de Alvarenga, o foco é no sujeito lírico - eu - que inicia o primeiro verso, ocupando uma posição sintática junto "aos deuses", atraindo o olhar do leitor para si e tornando ainda mais genérico e distante o "aquele" do texto latino. Essa transposição da terceira para a primeira pessoa é uma mudança muito forte e não ocorre em nenhuma outra tradução que Alvarenga transcreveu. É, em síntese, uma das grandes diferenças e originalidade da retradução de Lucas.

$\mathrm{Na}$ segunda estrofe, inicialmente, há uma mudança de focalização, incidindo esta nos risos de Cípria, mas nos demais versos o foco continua no sujeito lírico, especificamente nos efeitos que a visão da amada provoca nele. Em relação a isso, percebe-se outra inovação em relação ao texto latino. No texto de Catulo, o primeiro verso é ambíguo: o doce riso pode estar ligado aos dois últimos verbos da primeira estrofe e ser da pessoa amada, que ri docemente entretida com "Ille" ou do próprio "Ille" que observa e ouve a pessoa amada sorrindo. Além disso, o foco é na amada. Já na tradução de Alvarenga, não há essa ambiguidade: os risos da amada encantam o eu lírico. É importante reiterar que o quarto verso "Quod Loquar âmens" não existe em Catulo e têm essa ideia de falar (loquar)

a topicalização e a clivagem de sentenças, seja (b) por meio de expedientes prosódicos, como a Entonação, seja (c) com atuação concomitante dos dois (GONÇALVES, 1998, p. 32).

${ }^{10}$ Van Valin (1999 apud SOUZA, 2004, p. 47) destaca que o russo, o polonês, o latim e o português são línguas que apresentam uma estrutura sintática menos rígida e, por isso, a ordenação especial de constituintes aparece como uma das estratégias mais utilizadas para a marcação de Foco [...]. 
louco, demente, fora de si (amens). Daí, conclui-se que Magalhães e Alvarenga se utilizaram da mesma versão. Em contrapartida, outros editores preenchem essa lacuna com um verso em latim (vox in ore - voz na boca) com o sentido de "perco a voz ou a voz some da boca", como no Quadro 2. Essa solução está mais próxima do grego, Quadro 1. Assim, é uma diferença significativa entre as traduções portuguesas e as demais, francesas e inglesa.

$\mathrm{Na}$ terceira estrofe, descrevem-se os efeitos que a visão da amada provoca no eu lírico, sendo que, enquanto no texto latino o foco é no entorpecimento da fala, na tradução de Alvarenga ele incide nas veias, no sangue, que transportam a flama/fogo da paixão, provocando a audição de sons que não existem e o escurecimento da visão do sujeito. A opção por "flamma electrica" é uma escolha peculiar, já que ele comenta, em sua explanação sobre as traduções, que Safo era "dotada de uma alma chêa de electricidade [...]" (ALVARENGA, 1830, p. 107). Levando em consideração que, nessa época, a eletricidade ainda era considerada "coisa mágica", essa escolha liga tanto os efeitos da visão da amada, quanto a poetisa, ao universo do maravilhoso.

$\mathrm{Na}$ quarta estrofe, obra de Henri Estienne, continua-se a descrever esses efeitos. O enfoque no texto de Estienne é dado em suar (ação), já na tradução de Alvarenga é no suor (produto, resultado). Além disso, ele exclui o símile da relva desbotada, trocando-o por "pálida". Talvez porque a ideia do "velut herba pallent" pode, também, remeter ao campo semântico do medo e a leitura que Alvarenga adota para sua tradução é a de que todas essas reações no corpo do sujeito lírico foram provocadas pelo amor, não pelo ciúme ou medo de perder a pessoa amada, como comentado. Outro aspecto que marca a apropriação e a releitura de Alvarenga do texto latino são os dois últimos versos. Enquanto que na versão de 1742, o foco é na morte "[...] Orco / Proxima credor", no texto de Lucas, o foco é novamente no "Eu": "Eu morrer me sinto". Em síntese, tanto na cena inicial, quanto na final, o poema de Alvarenga converge para o "Eu", fato que o dota de uma subjetividade que não aparece no texto latino de 1742, embora o verbo "credor" esteja na primeira pessoa. 
E, se, por um lado, esse "eu" do verso final aproxima a tradução de Alvarenga da do Abade Delille e da de Fawkes; por outro, a presença dos termos "suor" e "tremor" afastam a brasileira das duas francesas. Esses dois termos estão presentes no grego (veja o Quadro 01), o que causa estranhamento ao fato de as traduções francesas desconsiderarem isso.

Como se vê, diante das ambiguidades presentes no fragmento da ode de Safo e mantidas na tradução para o latim, Alvarenga optou por focar no sujeito lírico na primeira cena. Esse sujeito considera igual ou superior aos deuses a pessoa que ouve ou vê a amada. Mas o eu lírico não se posiciona como um voyeur, já que essa consideração fica no plano das ideias, em um plano abstrato. Em relação ao tipo de sentimento que provoca as sensações no eu lírico, ele opta pela visão mais corrente: a do amor, o que vai ao encontro da sua escolha em relação à primeira cena.

Embora adote a visão mais corrente, é possível perceber, na retradução de Alvarenga, marcas de autoria, mas de uma autoria “derivada, não inerente" (VENUTI, 1996, p. 121). Um exemplo disso é a mudança do foco da terceira para a primeira pessoa, que sintoniza com as questões contemporâneas à sua época, como a ascensão da subjetividade na literatura provocadas pela onda romântica que já começava a se desenhar no Brasil.

\section{Considerações finais}

Analisou-se a retradução do Fragmento 31 de Safo, feita por Lucas José d'Alvarenga, em 1830, a partir de uma edição latina de 1742. Essa retradução reproduz a de Estienne, de 1586 que, por sua vez, baseou-se em Catulo. Todas apresentam inovações ou marcas de autoria em relação ao texto de Safo. Embora Alvarenga defenda que a tradução deva manter-se fiel ao texto original, ele introduz algumas modificações que marcam seu olhar oitocentista e que confirmam a posição de Venuti (1996), para quem a tradução é uma forma de autoria, embora derivada, não inerente. 


\section{Referências}

ALVARENGA, Lucas José de. Poezias. Rio de Janeiro: Ogier, 1830.

ANACREONTE. Anacreontis Teii Carmina. Londini: Imprensis S. Birt, 1742. Disponível em: < https://babel.hathitrust.org/cgi/pt?id=nyp.33433089885374;v iew $=1$ up;seq=1 > . Acesso em: 28 jul. 2017.

ANTUNES, Leonardo. Safo - Fr. 1 e Fr. 31. Nuntius Antiquus, Belo Horizonte, v. 4, p. 138-146, dez. 2009.

BERMAN, Antoine. A retradução como espaço da tradução. Trad. Clarissa Prado Marini e Marie-Hélène C. Torres. Cadernos de Tradução, Florianópolis, v. 37, n. 2, p. 261-268, ago. 2017. Disponível em: <https://periodicos.ufsc. br/index.php/traducao/article/view/2175-7968.2017v37n2p 261/34078>. Acesso em: 10 maio 2017.

CANDIDO, Antonio. Formação da literatura brasileira: momentos decisivos. 9. ed. Belo Horizonte: Itatitaia, 2000. 2 v.

CORNISH, F. W. Catullus, Tibullus and Peruigilium Veneris. London: William Heinemann, 1922.

ESTIENNE, Henri (Ed., org. e trad.). Pindari Olymphia, Pythia, Nemea, Isthmia. Genebra: Henri II Estienne, 1586. Disponível em: < http://www.e-rara. ch/doi/10.3931/e-rara-6563>. Acesso em: 28 jul. 2017.

FUJIHARA, Álvaro. Aspectos tradutórios em Terêncio. 2006. 69 f. Monografia (Bacharelado em Letras) - Faculdade de Ciências Humanas, Letras e Artes, Universidade Federal do Paraná, Curitiba, 2006.

FURLAN, Mauri. Brevíssima história da teoria da tradução no Ocidente. Cadernos de Tradução, Florianópolis, v. 2, n. 8, p. 11-28, 2001.

GONÇALVES, Carlos Alexandre. Foco e topicalização: delimitação e confronto de estruturas. Revista Estudos da Linguagem, Belo Horizonte, v. 7, n. 1, p. 
31-50, 1998. Disponível em: < http://www.periodicos.letras.ufmg.br/index.php/ relin/article/viewFile/2182/2121 >. Acesso em: 17 ago. 2017.

GRIMAL, P. Dicionário da Mitologia Grega e Romana. Rio de Janeiro: Bertrand Brasil, 2000.

OLIVA NETO, João. O Livro de Catulo. São Paulo: Edusp, 1996.

OLIVEIRA, G. I. Edição e estudo da novela Statira, e Zoroastes de Lucas José d'Alvarenga. 2016. 455p. Tese (Doutorado em Literatura Brasileira). Faculdade de Letras da Universidade Federal de Minas Gerais, Belo Horizonte, 2016.

POLT, Christopher Brian. Latin Literary translation in the Late Roman Republic. 2007. $183 \mathrm{f}$. Thesis (Master of Arts) - Department of Classics in the University of North Carolina, Chapel Hill, 2007.

SOUZA, Edson Rosa Francisco. Os advérbios focalizadores no português falado do Brasil: uma abordagem funcionalista. 2004. 176 f. Dissertação (Mestrado em Estudos Linguísticos) - Instituto de Biocências, Letras e Ciências Exatas da Universidade Estadual Paulista, São José do Rio Preto, 2004. Disponível em: $<$ http://citeseerx.ist.psu.edu/viewdoc/download?doi=10.1.1.628.3072\&rep $=$ rep $1 \&$ type $=$ pdf $>$. Acesso em: 17 ago. 2017.

VENUTI, Lawrence. O escândalo da tradução. TradTerm, São Paulo, v. 3, p. 99-122, 1996. Disponível em: < https://www.revistas.usp.br/tradterm/article/ view/49897>. Acesso em: 05 set. 2017.

WILLS, Gary. Sappho 31 and Catullus 51. Greek, Roman and Byzantine Studies, Durham, v. 8, n. 3, p. 167-197, 1967.

Recebido em: 27/04/2018

Aceito em: 09/07/2018

Publicado em setembro de 2018

Felipe Coelho de Souza Ladeira. E-mail: ostrogodos@hotmail.com ORCID: https://orcid.org/0000-0003-3652-6357

Gracinéa Imaculada Oliveira. E-mail: gracineaoliveira@hotmail.com ORCID: http://orcid.org/0000-0002-6841-8273 